\title{
Fixando os marcos: Carvalho Calero e o criterio filolóxico
}

\author{
Mario Regueira \\ Universidade de Santiago de Compostela \\ [Recibido, 27 abril 2020; aceptado, 4 xuño 2020]
}

\begin{abstract}
[Regueira, M. (2020). Fixando os marcos: Carvalho Calero e o criterio filolóxico. Boletín Galego de Literatura, 56, "Notas", 23-34]

DOI http://dx.doi.org/10.15304/bgl.56.6783
\end{abstract}

RESUMO Na presente nota realízase unha análise do papel de Ricardo Carvalho Calero (Ferrol, 1910-Santiago de Compostela, 1990) na fixación do criterio filolóxico que rexería para a literatura galega de posguerra a través da súa obra de creación literaria.

PALABRAS CHAVE Carvalho Calero; criterio filolóxico; literatura galega; posguerra; creación literaria.

ABSTRACT In the present note will be carried out an analysis of Ricardo Carvalho Calero's role in the process of establishing the philological criterion which regulated Galician literature in the post-Civil War through his literary works.

KEYWORDS Carvalho Calero; philological criterion, Galician Literature; post-Civil War; literary work.

Cando en 1948, a editorial Bibliófilos Gallegos convoca o seu "Premio de Novela Gallega" faino nun contexto dificultoso e, en certo sentido, contra o espírito dun proxecto asociado á bibliofilia e o libro antigo dende o propio nome. Tratábase dun ámbito a medio camiño entre unha forma de supervivencia ${ }^{1}$ e un novo escenario para a cultura galega nos marcos do franquismo, unha asociación co histórico, o antigo e o patrimonial que figuras como Xosé Filgueira Valverde e Francisco Javier Sánchez Cantón, fundadores da editora, souberon usufrutuar tamén para outros proxectos propios. Se Bibliófilos acaba por editar $A$ xente da Barreira, de Ricardo Carvalho Calero, primeira novela de posguerra da literatura escrita en lingua galega, é por unha mestura de casualidade e peticións dunha contorna que xa entendía o seu camiño editorial como netamente insuficiente para as coordenadas políticas ás que se

1 Proxectos como a libraría e editorial Monterrey tamén camuflarían baixo o negocio do libro antigo e a reedición de antigüidades o seu compromiso galeguista. 
enfrontaba a nosa cultura. Xa durante o proceso de financiamento da editora Francisco Fernández del Riego (1948, p. 4) alertara do perigo deses "estériles caminos de arqueología literaria" que parecía anunciar o proxecto editorial. E non pode deslindarse esta crítica, vida dunha figura que, a pesar dela, era un dos seus subscritores, do feito de que Bibliófilos Gallegos incluíse este de "novela gallega" entre os premios dos seus primeiros anos de vida ${ }^{2}$.

A delimitación do obxecto a ser premiado é, porén, complexa: “[...] con libertad de tema y volumen. La cualidad de 'gallega' podrá provenir, indistintamente, de la lengua empleada, del carácter del asunto o de la naturaleza del autor" din as súas bases, unha definición que máis que negar a expresión literaria en lingua galega, decídese a reservarlle un sector de lexitimidade que concorre en igualdade con outros como a procedencia xeográfica ou mesmo o contido.

Cómpre lembrar que literatura en lingua galega, e especialmente a narrativa, ten nese momento como última referencia o campo literario dos anos 20 e 30, un ambiente de loita aberta por constituír un campo literario propio, e onde o campo ideolóxico galeguista efectúa unha forte influencia sobre a cultura, especialmente á hora de definir o que ese campo en emerxencia podía ser en tanto produto nacional. Un proceso que foi estudado polo miúdo por Antón Figueroa (2010, pp. 73-105; 2015, pp. 119-122) e no que se baralla unha autonomía do campo literario que comeza a apelar aos seus propios medios de delimitación, medios que o propio Ricardo Carvalho Calero non dubida en vincular naquel momento á lingua: "Ó decir galega entendo, como é natural, a poesía escrita na nosa lingoa vernácula” (1931, p. 53). Así, aínda que Carvalho Calero apele tamén nesa altura ao "espríto racial” (1931, p. 54), non cabe dúbida de que comeza a configurar o que Antón Figueroa define como "o máis potente [...] instrumento de identificación" (2010, p. 106). A lingua constituiríase así como unha forma de reivindicar unha arte nacional fóra das servidumes que o programa estético do campo ideolóxico impuña: non é necesario imitar o folclore e refugar do cosmopolitismo para facer unha arte nacional: a lingua valida todas as súas expresións, mesmo as máis influídas por correntes estranxeiras.

2 Premios dedicados a tradución, neste caso de obras clásicas ou antigas que puidesen ser editadas nas marxes lexislativas do franquismo (1951) e á recollida de refráns (en 1952 é declarado deserto e volve convocarse en 1953). 
O panorama, a finais dos anos 40 e comezos dos 50, non pode ser máis diferente a aquel que entrevemos na efervescencia previa á Guerra Civil. Con todo o tecido editorial galeguista destruído na contenda, o papel que o franquismo reserva á literatura escrita en galego non ten unha soa interpretación, aínda que podemos dicir que a súa posibilidade pasa máis pola domesticación que por unha simple prohibición con tons de exterminio cultural. A literatura escrita en galego pasa a ser delimitada dende o poder como un produto lírico, de filiación sentimental ou asociado a conceptos de antigüidade. Non é unha lingua para todos os ámbitos, nin sequera dentro do literario: para escribir literatura vangardista ou ensaio filosófico xa está a lingua castelá, e o galego queda reducido a esas vinculacións cun tempo arcaico, xunto co consabido sentimentalismo que vai asociado á suposta "alma lírica" do noso pobo e que converte a poesía galega de posguerra nun elemento relativamente inocuo ${ }^{3}$ para o réxime.

Resulta evidente así que, nas inmediacións do franquismo ideolóxico, "literatura galega" é un concepto que nunca máis deberá asociarse a un criterio filolóxico exclusivo, unha vez que este ten potencialmente a capacidade de devolverlle á nosa lingua todos eses usos vetados. Tamén pola innegábel homoloxía literario-política que existe na definición dun campo exclusivamente galego fronte a outro exclusivamente castelán.

Non se trata, por parte de Bibliófilos Gallegos, da única tentativa neste sentido nese período. Tan só uns anos despois, coincidindo coa publicación da novela gañadora do premio, a editora acolle o primeiro volume do Diccionario Bio-Bibliográfico de Escritores de Antonio Couceiro Freijomil. Publicado en tres volumes entre 1951 e 1954, o Diccionario constrúese cun criterio que lembra poderosamente o que marca este primeiro premio de "novela gallega": unha noción de "literatura galega" que se refire principalmente ao xeográfico, sen por iso desbotar, naturalmente, as figuras que escribiron en galego, pero acollendo tamén algunhas que só serían galegas por herdanza ou por preocupación polos temas da terra. Os problemas metodolóxicos da obra de Couceiro

3 Cabe relacionar con esta permisividade a relativa complicidade de cargos franquistas que trufan a existencia da colección Benito Soto (Regueira, 2020, p. 24) e resolven os problemas legais que teñen algunhas edicións, como a de Cómaros verdes (1947) de Aquilino Iglesia Alvariño (Regueira, 2020 , p. 20). É unha actitude que, porén, non se mantén constante, e ás veces os mesmos actores viran cara á desconfianza e a limitación noutros episodios editoriais posteriores que teñen a lingua galega como protagonista. 
Freijomil son abondosos, e producen situacións delirantes como a inclusión de Francisco e Ramón Franco Bahamonde nesa nómina de "escritores” galegos (Couceiro Freijomil: 1952, pp. 102-103). Porén, resulta relevante a análise da obra realizada por Helena Miguélez-Carballeira, que a cualifica de "masculine revenge fantasy against the men of pre-war Galician nationalism" (Miguélez-Carballeira, 2013, p. 130). Unha sorte de axuste de contas do autor contra o ambiente do galeguismo de pre-guerra, co que xa tivera discrepancias, e que aproveita a situación de redefinición do papel da cultura galega que se dá na posguerra para facer unha clasificación que, apoiada en estruturas ben vistas polo réxime, ten moitas posibilidades de acabar sendo normativa. A proposta de Couceiro Freijomil non vai só contra o criterio filolóxico, tamén apoiaría profundamente a redución da identidade galega aos termos líricos e sentimentais que lle reserva o programa da ditadura franquista.

É necesario indicar porén, que se a noción do criterio filolóxico constitúe unha ferramenta decisiva para a autonomización do campo literario galego de pre-guerra, consideramos que o seu status como factor indiscutíbel aínda está lonxe de ser estabelecida. Isto é palpábel tamén na estratexia que o galeguismo supervivente no interior trata de desenvolver a través da editorial Galaxia. A actitude das persoas vinculadas a Galaxia e dos proxectos da editora ao respecto do criterio filolóxico é oscilante, unha indefinición que só parcialmente pode relacionarse coa necesidade de sobrevivir como tentativa cultural baixo a ditadura. A esa última situación podería atribuírse o feito de que a Colección Grial, a primeira etapa da revista, que trata de camuflarse como unha colección de monografías para sortear a lexislación que impide unha publicación periódica en galego, acolla figuras clásicas da literatura de expresión castelá, ás veces na portada ${ }^{4}$. Tamén é este factor o que pode explicar que a colección de "Manuais" de Galaxia estea editada en castelán, pois o ensaio tiña máis dificultades para validarse no seu emprego da lingua vernácula que outras formas de creación literaria ${ }^{5}$. Hai outros factores, porén, que indican que a posibilidade de definir a literatura galega en clave non filolóxica, vai máis aló da necesidade de non chamar a atención do réxime. En particular, que a primeira ferramenta de historiografía literaria da editora, o Manual de Historia de la Literatura Gallega (1951b) de Francisco Fernández

4 É o caso do terceiro número: "Presencia de Curros y Doña Emilia" (1951), onde Curros Enríquez comparte protagonismo con Emilia Pardo Bazán.

5 Como deixa ben claro o affaire acontecido coa tradución de Da esencia da verdade de Martin Heidegger (Regueira, pp. 105-106). 
del Riego, apele a autores de expresión castelá é algo a ter en conta, mesmo aceptando o papel secundario destes. É igualmente rechamante que unha das críticas que recibe este volume, asinada por un Neumandro que agocha a Ánxel Fole, resalte que "En toda Historia de la Literatura, por elemental que sea, la ingente obra del genial D. Ramón del Valle Inclán, tan sustancialmente nuestra, reclama un amplio y detallado examen. ¿Como es posible «liquidar» todo su asombroso teatro en media página?" (Fole, 1951, p. 81). Se no Manual de Historia de Fernández del Riego o criterio é non filolóxico, as súas páxinas reservan os lugares principais á produción en galego, secundarizando as obras producidas en castelán, unha tendencia que se acentúa, sen mudar por iso o criterio de descrición da literatura galega, na refección da obra que, xa en galego, se publica en data tan tardía como 1971.

Atopamos nestas perspectivas un debate latente que se dá no seo da cultura galega: por unha banda a necesidade de reivindicar un campo literario propio que evite o risco patente de ser absorbido ou folclorizado polo campo cultural castelán, nese momento dominado pola ditadura. Por outra, o grande valor estratéxico que manteñen figuras universais que son recoñecidas no ámbito ibérico pola súa obra noutra lingua. Tal sería o caso de Ramón del Valle Inclán ou Emilia Pardo Bazán, un capital simbólico ao que pode engadirse a produción en castelán de figuras centrais do canon galeguista como Rosalía de Castro. Da mesma forma, non é banal a construción, durante os primeiros anos de Galaxia e moi particularmente na obra do seu director Ramón Piñeiro (1956, pp. 11-26; 1959, p. 13) dun "programa étnico" que define a literatura galega como adecuación a unha serie de características esenciais e que ten a posibilidade potencial de competir co criterio filolóxico (Regueira, 2020, pp. 148-162). Con todo, ningunha destas vacilacións nega o compromiso principal de Galaxia e do seu círculo coa produción literaria en lingua galega e a súa consideración de produto prioritario na súa definición do campo, cousas claramente ausentes das tentativas de proxectos como o de Bibliófilos Gallegos, máis dispostos a un pacto acomodado cos parámetros da ditadura e a súa consideración folclórica e subalterna da lingua galega.

\section{Elena Quiroga e Ricardo Carvalho Calero, dous modelos autoriais}

Esa situación, entendida tamén nas coordenadas posibilistas de finais dos anos corenta, cando a editorial Galaxia non pasa de ser un simple proxecto, fai 
que o Premio de Bibliófilos represente unha oportunidade importante para o círculo galeguista que despois rexerá os destinos da editora. O xurado estará formado por Ramón Cabanillas, Ramón Otero Pedrayo, Francisco Serrano Castilla, José Guerra Campos, Francisco Fernández del Riego e Raimundo García Domínguez "Borobó”, unha mestura de afinidades galeguistas, algunhas delas cun histórico de represalias por parte do réxime, con outras completamente afíns a este ${ }^{6}$. Unha composición que denota tamén a necesidade de validación que un proxecto como o de Bibliófilos Gallegos precisaba, tanto de parte das novas estruturas políticas como do vello galeguismo e os representantes culturais que sobrevivían no interior. O tema lingüístico é algo que aparece frecuentemente na correspondencia dos que, moi pouco tempo despois, estarán na órbita da Editorial Galaxia. En decembro de 1949, Ramón Piñeiro escríbelle a Fernández del Riego, sobre o premio: "A única obra que está en galego coido que é a de Ricardo, que é galega pola lingua, polo tema e polo autor. Se o concurso foi creado para estimular a creación de novelas galegas [...], supoño que o feito de estar escrita en galego será un tanto a favor en relación coas demais" (Dasilva, 2010, p. 115). Trátase dunha interpretación dunhas bases problemáticas cuxa polémica non tardará en prolongarse.

A xente da Barreira de Carvalho Calero consegue gañar o certame con catro votos a favor, un en contra e unha abstención. As dúbidas sobre a súa calidade non deixan de manifestarse durante o tempo previo a este fallo na correspondencia privada de Fernández del Riego: "desde o meu punto de vista, hai, polo menos, unha rival da de Carballo, que novelisticamente aventaxa a ista" (Alonso Montero, 2015, p. 236-237), escríbelle a Otero Pedrayo en febreiro de 1950. Unha semana antes do 22 de abril, data que figura na acta do premio, Piñeiro segue a barallar con Fernández del Riego a competencia narrativa de Carvalho Calero: "Nunca me pareceu que tivese madeira de novelista. [...]. Mellor sería que esta oportunidade servise para dar un importante paso na política de prestixiamento literario da nosa lingua, mais nin é culpa túa nin dos demais xurados que non se presentase unha obra merescente de lle prestar ese alto servizo á nosa cultura [...]” (Dasilva, 2010, p. 115). A vitoria de Carvalho Calero, en calquera caso, é lida como un triunfo por parte dos galeguistas, exultantes, especialmente no seu discurso privado, de poder demostrar que o galego segue a ser unha lingua válida para a creación litera-

6 Guerra Campos era un sacerdote que encaixaba co nacional-catolicismo do réxime, e Serrano Castilla un coñecido falanxista. 
ria distinta dos usos folclóricos e líricos impostos, tanto polo contexto xeral, como por ataques puntuais ${ }^{7}$ do mundo cultural. Trátase dunha perspectiva que tamén aparece destacada pola prensa, El Correo Gallego do 23 de abril de 1950 dá conta minuciosa das deliberacións do premio e dos seus finalistas, destacando que a gañadora resultou finalmente a única novela presentada en galego: "La prosa gallega alcanza en la obra premiada un punto de madurez y sobriedad que señalará una etapa en la evolución de nuestra lengua materna" (El Correo Gallego, 1950, p. 2). Non cabe dúbida de que a posibilidade de continuidade dunha literatura escrita en lingua galega supuña un tema aberto nos círculos culturais da época, con distintos posicionamentos ao respecto. Neste sentido, a revista $A l b a$, acolle no seu número 5 dous relatos relacionados co premio:

Recientemente la Editorial Compostelana Bibliófilos Gallegos, convocó un concurso de novela en el que resultó premiado Ricardo Carballo Calero por su novela "XENTE DA BARREIRA".

El jurado consideró, entre otras, como recomendable la novela de Elena Quiroga de Abarca de la Válgoma, titulada "TUMBA LOUREIRO"

Ambos novelistas han escrito, expresamente para ALBA estas dos narraciones (Alonso Girgado, Castro Rodríguez, Domínguez Alberte e Eguizábal Gándara, 1995).

Ambos contos, tanto Os tumbos de Carvalho Calero, escrito en galego, como Vela al Viento de Elena Quiroga, que aparece en castelán, están escritos nunha primeira persoa que favorece un ton confesional e manteñen algunhas ligazóns co mundo do mar. A pesar de que a publicación non evidencia ningunha clase de enfrontamento, non resulta complexo imaxinar que ambos narradores comparecen convocados a unha especie de "duelo" literario, unha sorte de cata que permita comprobar en que medida a literatura galega pode desenvolverse de forma competente polos dous camiños potenciais que mantén abertos naquela altura. Poucos anos despois, o director de Alba, o berciano Ramón González-Alegre, acabará desvelando o seu propio posi-

7 Dasilva (2010, p. 115) destaca como o ano 1949 aparecen no xornal La Noche distintas descualificacións de Dámaso Alonso e Borobó sobre a posibilidade de que o galego fose algo máis que unha lingua poética, soidosa e folclórica (Borobó chega a pedir a prohibición de usos diferentes da poesía). Ironicamente o propio Borobó parece estar do lado dos galeguistas no xurado deste premio ao que alude directamente no seu artigo. É probábel que o propio estilo de $A$ xente da Barreira, que conectaba co xénero da "novela de pazo" e coa narrativa de Otero Pedrayo xogase un certo papel nisto, pois non se trataba da "novela post-freudiana" (García Domínguez, 1948, p. 4) que alude no seu artigo e marca unha certa transición posíbel dende eses empregos soidosos e folclorizantes. 
cionamento contrario ao criterio da lingua no debate sobre a cuestión filolóxica (Alonso Girgado, Castro Rodríguez, Domínguez Alberte e Eguizábal Gándara, 1995), así como as súas propias definicións favorábeis a unha consideración da lírica como algo "espiritualmente gallego" (González-Alegre, 1954, p. 8).

A polémica sobre o premio, non tarda, porén, en estenderse. A comezos de 1951 faise público que Elena Quiroga, unha das finalistas do Premio Bibliófilos Gallegos coa obra Tumba Loureiro resultou gañadora do prestixioso Premio Nadal cunha novela titulada Viento del norte. El Correo Gallego (9 de xaneiro de 1951, p.1) non tarda en destacar o feito, proclamando a identidade entre ambas as obras de Quiroga. Aléntase así unha polémica que debería ser resolta polo público: A xente da Barreira acababa de ser posta en circulación e tardaría pouco máis dun mes en coincidir con Viento del norte nas librarías. “¿Quien ganará [...] este gran «derby intelectual»?”, preguntan dende o xornal, nunha nova na que tamén é relevante a cuestión da galeguidade de Elena Quiroga, natural de Santander: "si no nació en Galicia, en ella nacieron sus padres, y en ella vive dende hace muchos años”. Ao día seguinte, o mesmo medio entrevista a Otero Pedrayo como membro do xurado de Bibliófilos: "el hecho de estar escrita en gallego -es mi opinión personal- era evidentemente un mérito. Pero no puede decidir sobre la bondad relativa de las obras" (El Correo Gallego, 10 de xaneiro de 1951, p. 5). A cuestión filolóxica considerase, por tanto, e seguindo as consideracións de Piñeiro, un mérito relativo, un factor que engade "galeguidade" e que dá unha perspectiva redonda á complexa cuestión do premio e das súas bases, xa que sería a única obra que cumpriría os tres criterios propostos.

Con argumentos literarios, e sen mencionar a cuestión da lingua, responde tamén Francisco Fernández del Riego (19 de xaneiro de 1951, p. 6), nun artigo que porén, relaciona a superioridade da novela de Carvalho Calero co manexo da tradición oteriana. Vincúlase así de novo a primeira novela en galego da posguerra co curso interrompido nos anos 30, cuxa última peza narrativa editada foi $O$ mesón dos ermos de Otero Pedrayo. Da mesma forma, Fernández del Riego reforza a decisión do xurado: tratándose ambas de dúas novelas "de pazo" cunha tentativa de protagonista colectivo, só $A$ xente da Barreira cumpriría con solvencia o seu proxecto narrativo. Esta resposta xa inclúe, nun post-scriptum o feito de que Tumba Loureiro e Viento del Norte non son, a dicir da súa autora, a mesma novela. 
Isto é o que estabelece a entrevista a Elena Quiroga que aparece en $E l$ Pueblo Gallego (Fraga de Lis e Quiroga, 1951, p. 5) o mesmo 19 de xaneiro, nunha resposta que parece airada, especialmente contra Otero Pedrayo e o "sensacionalismo" da prensa. Tumba Loureiro sería unha versión primeiriza e inacabada da que gañou o Nadal, e por tanto non debería ser xulgada unha pola outra. Porén, se algo chama a atención desta entrevista é a intensidade coa que a autora pretende vincularse e reivindicar a identidade galega, dunha forma que apela ao sentimentalismo: "llevo a Galicia en las entrañas" e que está trufada dos máis variados tópicos: o sobrenatural, o son do roncón, o contestar con preguntas... De forma propositada ou non, a visión folclorizante da identidade galega convive coa culpabilización desta dos seus propios males: "no, de Astorga para acá se desconoce Galicia y, ciertamente, por culpa de los gallegos. Se empeñan, en cuanto dejan atrás el paisaje nativo, de hacer de Galicia una exportación”. Perspectivas que, se poden ter en común cousas co programa do que serán os primeiros anos de Galaxia, encaixan tamén á perfección con esa posibilidade aberta de subalternidade pintoresca que o programa cultural do franquismo reserva á Galiza.

Carvalho Calero, pola súa parte, tamén é entrevistado nesas datas en $\mathrm{La}$ Noche a causa da cuestión: unha aparición na prensa na que podemos rastrear os ecos do pensamento galeguista de pre-guerra. Carvalho Calero defende a súa propia autonomía como escritor, parella á loita pola autonomía dun campo literario galego. A perspectiva de Carvalho Calero sobre o "duelo literario” con Quiroga tamén é relevante: “[...] está fuera de la realidad, porque no existe ni puede existir, ya que carece de base para ello". Ante un xornalista que insiste en que o Nadal podería ser gañado por A xente na Barreira, se a tivese traducido ao castelán, o de Ferrol manifesta o seu desinterese por ampliar o seu público coa tradución da obra: "no tengo afán de notoriedad y mucho menos de industrializar mi obra que es puramente una satisfacción espiritual. Solamente aspiro a enriquecer, dentro de lo posible, la literatura gallega." (Olano e Carvalho Calero, 1951, p. 5).

A polémica, sen dúbida esporeada pola prensa galega nun contexto onde este tipo de novas non eran moi habituais, deixa as cuestión dos límites da "literatura galega" abertos e dá unha repercusión inesperada á decisión do xurado, provocando que varios dos seus membros xustifiquen a decisión sen apelar directamente á centralidade do criterio filolóxico. Felipe Cordero Carrete, membro de Bibliófilos Gallegos, aínda escribirá o 9 de xaneiro a 
Filgueira Valverde: “¿Conveniente este jaleo? Yo creo que sí. Le da publicidad a la novela de Carballo Calero. ¿En que lugar deja al jurado? Entre nosotros, creo que no muy bien, a menos que se opine que había de premiarse a una novela en gallego fuese como fuese" (Dasilva, 2010, p. 116).

A cuestión sobre o criterio filolóxico abríase nas formas posíbeis baixo a férrea presión da ditadura. A mesma configuración do premio de Bibliófilos non deixa de representar a incapacidade de xestionar un debate latente na sociedade literaria galega que acaba por resolverse dunha forma de aparencia espontánea pero baixo a que podemos percibir as fortes correntes de pensamento que pulan, e pularán durante os próximos anos, entre dous modelos de definición da literatura galega: o criterio filolóxico como garantía preliminar dunha autonomía de campo por construír, ou o criterio aberto que encaixa principalmente nunha visión folclorizante e non conflitiva co programa cultural do franquismo ${ }^{8}$. Non deixa de resultar irónico que, nos anos por vir, sexa precisamente Carvalho Calero, un dos protagonistas deste affaire, a persoa que máis pulará co seu traballo de investigación ${ }^{9}$ pola delimitación filolóxica da literatura galega, rexeitando tanto solucións intermedias, como as propostas, con ambición autonomizadora, polo círculo de Galaxia (Fernández del Riego, 1951b), como aquelas outras que remarcaban a subalternidade da produción en galego, como as do ámbito de Bibliófilos Gallegos (Couceiro Freijomil, 1951) e outras feitas de forma independente (Varela Jácome, 1951).

Elena Quiroga, pola súa parte, continúa unha prolífica carreira como novelista en castelán. No momento no que ingresa na Real Academia Española, en 1983, cun discurso sobre Álvaro Cunqueiro e sendo unha das primeiras mulleres en formar parte da institución, o debate sobre a pertenza da súa

8 O debate sobre este criterio terá varios episodios explícitos nos anos seguintes. A forma na que aparece neste feito concreto, onde máis ben se rastrea entre o non dito e o mencionado entre liñas, pode relacionarse parcialmente co anti-intelectualismo mencionado por Antón Figueroa (2010, pp. 70-71) como unha ferramenta útil para determinados actores en certos contextos. É certo que a presión da ditadura dificultaba a aparición dun debate explícito, especialmente neste momento concreto, pero tamén é certo que as bases de delimitación do campo aspiran sempre a aparecer como "naturais", e por tanto podemos entender que tamén esta ausencia de problematización específica xoga o seu papel nese sentido.

9 Un traballo que ten a súa principal referencia en Historia da Literatura Galega Contemporánea I (Carvalho Calero, 1963), pero que xa podemos atopar en obras que dan base a esta como Aportaciones fundamentales a la literatura gallega contemporánea (Carvalho Calero, 1955a) ou Sete poetas galegos (Carvalho Calero, 1955b). 
obra á "literatura galega" ten unha entidade notabelmente menos relevante. A autora, falece en 1995 na Coruña, só cinco anos despois de que o seu rival literario de antano o fixese en Santiago de Compostela. A biblioteca persoal de cada un deles está hoxe baixo custodia do Parlamento de Galicia.

\section{Bibliografía}

Alonso Girgado, L., Castro Rodríguez, X., Domínguez Alberte, X. C., e Eguizábal Gándara, B. (1995). Alba: hojas de poesíalfollas de poesía : a Coruña, 1948 - Vigo, 1956. Xunta de Galicia e Publicacións do Centro de investigacións lingüísticas e literarias Ramón Piñeiro.

Alonso Montero, X. (2015). Xosé Filgueira Valverde. Biografía intelectual. Edicións Xerais de Galicia.

Carvalho Calero, R. (1931). Ollada encol da poesía líriga galega contemporánea. Nós, 87.

Carvalho Calero, R. (1955a). Aportaciones fundamentales a la literatura gallega contemporánea. Gredos.

Carvalho Calero, R. (1955b). Sete poetas galegos: Rosalía de Castro, Eduardo Pondal, Manuel Curros Enríquez, Antonio Noriega Varela, Ramón Cabanillas, Luis Amado Carballo, Manuel Antonio. Galaxia.

Carvalho Calero, R. (1963). Historia da Literatura Galega Contemporánea I. Galaxia.

Couceiro Freijomil, A. (1951-1954). Diccionario bio-bibliográfico de escritores [3 volumes]. Bibliófilos Gallegos.

Dasilva, X. M. (2010). Ramón Piñeiro e o "Cancioeiro" de Pokorny: Anatomía dun certame de tradución. Grial, 185, 111-123.

El Correo Gallego (10 de xaneiro de 1951). Una opinión de peso sobre el tema literario de actualidad. El Correo Gallego.

El Correo Gallego (23 de abril de 1950). "A xente da Barreira" original de Ricardo Carballo Calero gana el Premio de Novela instituído por la Sociedad de Bibliófilos Gallegos. El Correo Gallego.

El Correo Gallego (9 de xaneiro de 1951). El Premio Nadal pudo haber caído en Santiago. El Correo Gallego. 
Fernández del Riego, F. (19 de xaneiro de 1951). Dos novelas y dos premios. La Noche,

Fernández del Riego, F. (1951). Manual de Historia de la Literatura Gallega. Galaxia.

Fernández del Riego, F. (1971). Manual de Historia da Literatura Galega. Galaxia.

Fernández del Riego, F. (30 de xaneiro de 1948). Hacia la difusión de nuestros libros. La Noche.

Figueroa, A. (2010). Ideoloxía e autonomía no campo literario galego. Laiovento.

Figueroa, A. (2015). Marxes e centros. Para unha socioloxía do campo cultural. Laiovento.

Fole, Á. (1951). Crítica de una «Historia de la Literatura Gallega». En R. Carvalho Calero, J. L. Varela, P. Abuín e M. María, Presencia de Curros y Da Emilia [Colección Grial, 3] (pp. 70-81). Galaxia.

Fraga de Lis, M. e Quiroga, E. (19 de xaneiro de 1951). El ambiente gallego, primer protagonista de "Viento del Norte". El Pueblo Gallego.

García Domínguez, R. (22 de setembro de 1948). Novelemos en neo-castellano. La Noche.

González-Alegre, R. (1954). Poesía gallega contemporánea. Ensayo sobre literatura gallega. Gráficas Torres.

Miguélez-Carballeira, H. (2013). Galicia, a Sentimental Nation Gender, Culture and Politics. University of Wales Press.

Olano e Carvalho Calero, R. (23 de xaneiro de 1951). Carballo Calero, el novelista que "provocó" el Premio Nadal. La Noche.

Piñeiro, R. (1956). Carta a Daniel Cortezón Álvarez. En D. Cortezón, As covas do Rei Cintolo (pp. 11-26). Galaxia.

Piñeiro, R. (1959). Factores esenciales de la literatura gallega. Ínsula, 152-153, 13.

Quiroga, E. (1951). Viento del norte. Ediciones Destino.

Regueira, M. 2020. Narrativa e imaxinario nacional na reconstrución do campo literario de posguerra (1936-1966). Xerais.

Varela Jácome, B. 1951. Historia de la literatura gallega. Porto y Cía Editores. 